\title{
MODELLING THE UNIVERSITI MALAYSIA PAHANG EXAMINATION TIMETABLING PROBLEM
}

\author{
Ling-Shing Chang ${ }^{a}$, M N M Kahar ${ }^{a, b}$ \\ ${ }^{a}$ Faculty of Computer Systems \& Software Engineering, Universiti Malaysia Pahang, \\ Kuantan, Pahang, Malaysia. \\ ${ }^{b}$ Soft Computing \& Intelligent System Research Group (SPINT), Faculty of Computer \\ Systems \& Software Engineering, Universiti Malaysia Pahang, Kuantan, Pahang, \\ Malaysia \\ E-Mail: lingshing_chang@msn.com,mnizam@ump.edu.my
}

\begin{abstract}
This paper presents a study of the Universiti Malaysia Pahang (UMP) examination timetabling problem and its constraints. UMP currently situated in two campuses (Gambang and Pekan) which presents many challenges in producing examination timetable. The UMP examination timetabling problem consists of new constraints that have not been investigated before in the literature, that include scheduled exams into the appropriate campus. The additional constraints increase the level of difficulty in producing a high quality examination timetable. Additionally, having no formal mathematical model leads to difficulty in determining the quality of the produced examination timetable. This paper investigates the UMP examination timetabling constraints and develop the formal mathematical model to determine the quality of the generated examination timetable. The developed formal model able to evaluated the UMP examination timetable quality (produced by UMP's proprietary system). The result reveals a high penalty value (bad quality) and unsatisfaction of the hard constraints.
\end{abstract}

Keywords: Examination timetabling, constraints, mathematical model

\section{INTRODUCTION}

Examination timetabling is an important event that is required in all academic institution. Examination timetabling is a task of allocating examinations to the specific timeslots and rooms by fulfilling the constraints. There are two main categories of constraints that need to be considered in producing the examination timetable, namely hard and soft constraints. The hard constraints are those requirements that cannot be broken and must be satisfied at all times. For example, no students are allowed to sit two examinations simultaneously. The soft constraints refer to those requirements that should be satisfied as much as possible (Ayob et al., 2007). For example, as much as possible the examinations need to be spread out so that students have sufficient study time between the exams. Hence, the soft constraints (or so called objective function) are used to evaluate the quality of the timetable. In the objective function, each soft constraint is assigned to a penalty value, and the total penalty value needs to be minimised. (Abdullah \& Turabieh, 2012; Ayob et al., 2007). 
The examination timetabling problem can be divided into two categories which are un-capacitated problem and capacitated problem. The un-capacitated problem does not consider the room capacity while the capacitated problem considers it as one of the hard constraint (Abdullah, 2006; Pillay and Banzhaf, 2009). Burke et al., (1996) stated that $73 \%$ of universities reported that allocating room for examinations is a major problem. Therefore, the capacitated problems are more complex and challenging to solve compared to the un-capacitated problems. Capacitated problem resemble the realworld problem as it considers the room capacities as a hard constraint. The room constraint increases the level of complexity to the overall problem in producing a high quality examination timetable.

In this paper, we present a study of Universiti Malaysia Pahang (UMP) examination timetabling problem which consists different constraints from the literature. The related work of the benchmark dataset is presented in Section II. In Section III, the UMP examination timetabling problem and its constraints are presented. In Section IV, the formal model of the UMP examination timetabling problem is discussed. In Section V, the relationship between the constraints and the models are discussed. The experimental setup is presented in Section VI. The discussion on the results is in Section VII, and the conclusion is presented in Section VIII.

\section{RELATED WORK}

The most common examination timetabling datasets are Toronto dataset (Carter, Laporte, \& Lee, 1996), the dataset from University of Nottingham (Burke, Newall, \& Weare, 1996) and dataset from University of Melbourne (Merlot, Boland, Hughes, \& Stuckey, 2003). In addition, a few newer examination timetabling datasets have been proposed, for example is the 2007 Second International Timetabling Competition (refer to as ITC2007) dataset (McCollum et al., 2008), dataset from UiTM (Kendall \& Hussin, 2004; Hussin, 2005), dataset from UKM (Ayob et al., 2007) and dataset from UMP (Kahar \& Kendall, 2010). The Toronto dataset is an uncapacitated examination timetabling problems from thirteen different academic institutions around the world (Carter, Laporte, \& Lee, 1996). These datasets differ in term of the number of examinations, timeslots and registered students as well as the conflict density. For example, instance car-s-91 consists of 35 timeslots, 682 examinations, 16925 students and conflict density is 0.13 while instance car-f-92 consists of 32 timeslots, 543 examinations, 18419 students and conflict density is 0.14 . The constraints of the Toronto dataset include clash free and spread the examinations that are the hard constraints and soft constraints respectively. Many researchers have investigated Toronto dataset including Abdullah et al., 2010; Sabar et al., 2012a; Burke and Bykov, 2012; Alzaqebah and Abdullah, 2014; Turabieh and Abdullah, 2011 b.

The Nottingham dataset was introduced by Burke, Newall, \& Weare (1996). Nottingham dataset is a capacitated problem which consists of 7896 students, 23265 student enrolments, 1550 room capacities, 0.03 conflict density with three timeslots a day where the total number of timeslots is 23. The objective of the Nottingham dataset is to reduce the back-to-back exams on the same day (Burke \& Newall, 1999)

Merlot et al., (2003) introduced a dataset from University of Melbourne. They presented two capacitated datasets which are from semester I and II in 2001. Semester I has 521 examinations, 28 timeslots, 20656 registered students and 62248 student 
enrolments while semester II has 562 examinations, 31 timeslots, 19816 registered students and 60637 student enrolments. There are two timeslots on every weekday and different capacity for each timeslot. The objective of the dataset is to minimise the backto-back exams on the same day or overnight.

The second international timetabling competition (ITC2007) dataset was published in August 2007 during the Second International Timetabling Competition. Twelve datasets were introduced with different conflict density, different number of examinations, students, timeslots and rooms. The ITC2007 examination dataset constraints include student are not allow to take two examinations simultaneously, the student capacity of the examinations scheduled should not exceed the room capacity, and the examinations should follow the specified arrangement. The objectives of the ITC2007 examination dataset are to minimise the back-to-back exams on the same day, timeslot and room usage, mixed examinations length in a timeslot and assigning as early as possible those larger examinations during the period of exam. Many researchers have investigated ITC2007 examination dataset including Gogos et al., 2012; Bykov and Petrovic, 2016; Alzaqebah and Abdullah, 2014; Battistutta et al., 2015; Anwar et al., 2013.

An uncapacitated dataset from UiTM Malaysia was introduced by Kendall and Hussin (2004). UiTM dataset consists of 2063 examinations, 84675 registered students, 357761 student enrolments and 40 timeslots. The constraints involve scheduling all the examinations with no clashing and as much as possible the examinations need to be spread out. The examinations that are scheduled during the weekend were penalised so that the examinations scheduled for the weekend can be minimised.

A capacitated dataset from UKM Malaysia was introduced by Ayob et al. (2007), and the requirement is that all the examinations must be scheduled. UKM dataset contains 818 examinations, 14047 registered students as well as 75857 student enrolments, 42 timeslots and 1550 room capacities. The room capacities for each room are different, for example, capacity for room DPBestari is 850 while for room DGemilang is 610. The constraints include no students sitting two examinations simultaneously and not allowing students taking three consecutive examinations in the same day. Besides, students seat consecutive exam must be allocated to the same exam room and avoid room sharing for specified examination. The objectives are spreading the examinations as much as possible and minimise the back-to-back exams on the same day.

A capacitated dataset from UMP Malaysia was introduced by Kahar and Kendall (2010). Two different datasets from semester 1 2007/2008 and semester 2 2008/2009 were presented. The dataset for semester 1 2007/2008 contains 157 examinations, 3550 registered students, 12731 student enrolments, 24 rooms and 0.05 conflict density while dataset for semester 2 2008/2009 contains 165 examinations, 4284 registered students, 1541 student enrolments, 28 rooms and 0.05 conflict density. They proposed two new constraints which are a single exam must be split into rooms in the same building only, and the distance between the rooms must be as close as possible. Besides, each room can only have one exam at each timeslot; UMP timetabling problem does not allow multiple examinations into the same room.

Table 1 shows a summary of examination datasets on the constraints. Toronto, Nottingham and Melbourne datasets are earlier datasets compared to the UiTM, UKM 
and UMP datasets. Based on the datasets and the constraints listed in Table 1, we found that different academic institutions have different constraints and requirements. UMP examination timetabling problem contains additional constraints which have not been investigated before in the literature. For example, the exam needs to be scheduled to the appropriate campus due to the fact of UMP has two separate campuses. 
Table 1 Summary of All Datasets on Constraints

\begin{tabular}{|c|c|c|c|c|c|c|c|c|c|}
\hline \multicolumn{2}{|r|}{ Constraints } & Toronto & $\begin{array}{l}\text { Nottingh } \\
\text { am }\end{array}$ & $\begin{array}{c}\text { Melbour } \\
\text { ne }\end{array}$ & UKM & UiTM & $\begin{array}{l}\text { ITC200 } \\
7\end{array}$ & $\begin{array}{c}\text { UMP } \\
(200708)\end{array}$ & $\begin{array}{c}\text { Our } \\
\text { dataset }\end{array}$ \\
\hline \multirow{5}{*}{ 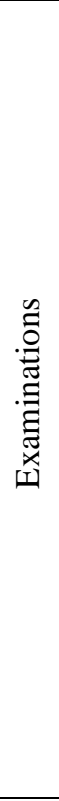 } & Clash-free & $\mathrm{H}$ & $\mathrm{H}$ & $\mathrm{H}$ & $\mathrm{H}$ & $\mathrm{H}$ & $\mathrm{H}$ & $\mathrm{H}$ & $\mathrm{H}$ \\
\hline & All exams scheduled only once & & $\mathrm{S}$ & $\mathrm{S}$ & $\mathrm{H}$ & $\mathrm{H}$ & & $\mathrm{H}$ & $\mathrm{H}$ \\
\hline & Weekend Scheduled & & & & & $S$ & & & \\
\hline & $\begin{array}{l}\text { Exam precedence } \\
\text { - specific arrangement: sa } \\
\text { - specific room: sr } \\
\text {-scheduled large exam first: If } \\
\text {-restriction on exam in specific } \\
\text { timeslot: } r t \\
\text {-scheduled combined exam in } \\
\text { the same timeslot: } c t \\
\text {-large capacity exam schedule } \\
\text { early during exam period: le }\end{array}$ & & & $\mathrm{H}(\mathrm{rt})$ & & $\mathrm{H}(\mathrm{ct})$ & $\begin{array}{l}\mathrm{H}(\mathrm{sa}) \\
\mathrm{S}(\mathrm{lf})\end{array}$ & & $\begin{array}{l}\mathrm{H}(\mathrm{rt}) \\
\mathrm{S}(\mathrm{le})\end{array}$ \\
\hline & $\begin{array}{l}\text { Consecutive exam } \\
\text {-two exams in a row: } 2 r \\
\text {-two exams in a day: } 2 d \\
\text {-two exams in a row overnight: } \\
2 n \\
\text {-three exams in a day: } 3 d\end{array}$ & & $\begin{array}{c}S \\
(2 \mathrm{~d} \& 2 \mathrm{n})\end{array}$ & $\begin{array}{c}S \\
(2 d \& 2 n)\end{array}$ & $\begin{array}{l}\mathrm{H}(3 \mathrm{~d}) \\
\mathrm{S}(2 \mathrm{r})\end{array}$ & & $\begin{array}{c}\mathrm{S} \\
(2 \mathrm{r} \& \\
2 \mathrm{~d})\end{array}$ & & \\
\hline \multirow{3}{*}{ 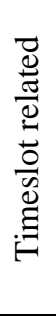 } & $\begin{array}{l}\text { Timeslot precedence } \\
\text {-minimize timeslot usage: tu }\end{array}$ & & & & & & $\mathrm{S}(\mathrm{tu})$ & & \\
\hline & $\begin{array}{l}\text { Timeslot length } \\
\text {-mixed exams length in a } \\
\text { timeslot: } m t\end{array}$ & & & & & & $\begin{array}{c}\mathrm{H} \\
\mathrm{S}(\mathrm{mt})\end{array}$ & & \\
\hline & $\begin{array}{l}\text { Spreading } \\
\text { - specific spread: ss }\end{array}$ & $S$ & $\mathrm{H}$ & $S$ & $\mathrm{~S}$ & $S$ & $\mathrm{~S}$ & S & $S$ \\
\hline \multirow{6}{*}{ 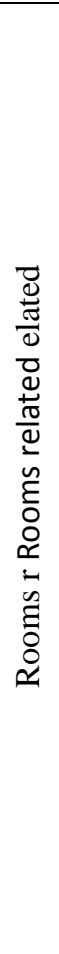 } & Distance of room & & & & & & & $S$ & $S$ \\
\hline & $\begin{array}{l}\text { Sharing of room with multiple } \\
\text { exams are not allow } \\
\text {-for specific exam only: se }\end{array}$ & & & & $\mathrm{H}$ & & & $\mathrm{H}$ & \\
\hline & $\begin{array}{l}\text { Sharing of room with multiple } \\
\text { exams are allow } \\
\text {-minimize sharing of exams } \\
\text { with different exam length: } d l\end{array}$ & & & & & & & & $S$ \\
\hline & $\begin{array}{l}\text { Room precedence } \\
\text { - assigned consecutive exam in } \\
\text { the same room: } \text { cr } \\
\text {-minimize room usage: } r u \\
\text {-specific campus: sc } \\
\text { - specific room: sr }\end{array}$ & & & & $\mathrm{H}(\mathrm{cr})$ & & $\begin{array}{l}\mathrm{H}(\mathrm{sr}) \\
\mathrm{S}(\mathrm{ru})\end{array}$ & & $\mathrm{H}(\mathrm{sc})$ \\
\hline & $\begin{array}{l}\text { A single exam split into } \\
\text { different rooms } \\
\text {-same building: } s b \\
\text {-as close as possible: } c p\end{array}$ & & & & & & & $\begin{array}{l}\mathrm{H}(\mathrm{sb}) \\
\mathrm{S}(\mathrm{cp})\end{array}$ & $\begin{array}{l}\mathrm{H}(\mathrm{sb}) \\
\mathrm{S}(\mathrm{cp})\end{array}$ \\
\hline & $\begin{array}{l}\text { Room capacity } \\
\text {-total seats: } t \text { s } \\
\text {-individual room: ir }\end{array}$ & & $\mathrm{H}(\mathrm{ts})$ & $\mathrm{H}(\mathrm{ts})$ & $\begin{array}{c}\mathrm{H} \\
\text { (ts \& ir) }\end{array}$ & & $\mathrm{H}$ (ir) & $\mathrm{H}$ (ir) & $\mathrm{H}$ (ir) \\
\hline
\end{tabular}

$*(\mathrm{H}=$ Hard constraint; $\mathrm{S}=$ Soft constraint $)$ 


\section{UNIVERSITI MALAYSIA PAHANG (UMP) EXAMINATION TIMETABLING PROBLEM}

The Universiti Malaysia Pahang (UMP) is initially named as Kolej Universiti Kejuruteraan dan Teknologi Malaysia (KUKTEM), was established on February 16, 2002, and is located in the east coast state of Pahang. In 2007, UMP contained five faculties and 3550 students and these faculties are offered a total of 17 programs. However, an increase in the number of faculties to nine faculties in 2014 and with a total number of students increases to 7833 .

UMP currently situated in two campuses (Gambang and Pekan) which presents many challenges in producing an examination timetable. Moreover, UMP examination timetabling problem is a capacitated problem which contains commonly used constraints and additional constraints. Table 2 describes the constraints for the UMP examination timetabling problem.

Table 2 Constraints for UMP Examination Timetabling Problem

\begin{tabular}{|c|c|}
\hline Hard Constraints & Soft Constraints \\
\hline $\begin{array}{l}\text { H1: No students are allowed to take more } \\
\text { than one examination simultaneously. } \\
\text { H2: The number of students allocated to } \\
\text { an exam room must be less than the } \\
\text { maximum capacity of room. } \\
\text { H3: Exam room can be shared with } \\
\text { multiple exam papers. } \\
\text { H4: A single exam must be split into } \\
\text { rooms in the same building. } \\
\text { H5: The exam needs to be scheduled to } \\
\text { the appropriate campus. }\end{array}$ & $\begin{array}{l}\text { S1: The exam needs to be spread out } \\
\text { evenly throughout the period of } \\
\text { exam. } \\
\text { S2: The rooms distance for a single } \\
\text { exam should be as close as } \\
\text { possible. } \\
\text { S3: Splitting an exam into multiple } \\
\text { rooms should be minimized }\end{array}$ \\
\hline
\end{tabular}

In UMP, a proprietary system has been used to produce the examination timetable since year 2003 . The proprietary system managed to produce the examination timetable but it is unable to determine the quality of the timetable generated. This is because the proprietary system has no mathematical model to evaluate the quality of the examination timetable generated. Hence, this motivates us to develop a formal model of the UMP examination timetabling problem.

\section{FORMAL MODEL OF THE UMP EXAMINATION TIMETABLING PROBLEM}

In this section, we discuss the formal model of the UMP examination timetabling problem.

Incides

$$
i, j \quad 1 \ldots \mathrm{N}
$$




$$
\begin{array}{ll}
r, p & 1 \ldots \mathrm{R} \\
\mathrm{s} & 1 \ldots \mathrm{S} \\
\mathrm{t} & 1 \ldots \mathrm{T}
\end{array}
$$

Parameters

$\mathrm{N} \quad$ Number of exams

$\mathrm{R} \quad$ Number of rooms

$\mathrm{S} \quad$ Number of registered students

$\mathrm{T} \quad$ Number of timeslots

$S_{i} \quad$ Number of registered students for exam $i$

$R_{\mathrm{t}} \quad$ Number of rooms available at timeslot $t$

$c_{i} \quad$ Campus location for exam $i$

$C_{r} \quad$ Campus location for room $r$

$B_{r} \quad$ Building for room $r$

$f_{\mathrm{r}} \quad$ Total capacity for room $r$

$c_{i j}$ Conflict matrix where each element $\left(c_{i j}, i, j \in\{1 \ldots N\}\right.$ represents the number of students that have to be both exams $i$ and $j$.

$a_{+p}$ Distance matrix where each element (denoted by $a_{+p}, r, p \in\{1 \ldots R\}$ ) is the distance between rooms $r$ and $p$.

Decision variables

$x_{\text {it }} \quad 1$ if examination $i$ is assigned to timeslot $t, 0$ otherwise

$y_{i r} \quad 1$ if examination $i$ is assigned to room $r, 0$ otherwise

$z_{\mathrm{rt}} \quad 1$ if room $r$ is assigned to timeslot $t, 0$ otherwise.

Three objectives are used to evaluate the timetable quality. The objectives are to spread out the examinations throughout the exam period, to minimize the rooms distance for a single exam and to minimize splitting of rooms for a single exam. The formulation is shown as bellow:

$$
\text { (Minimize) } F(x)=F_{1}+F_{2}+F_{3}
$$

The first component of cost, spreading cost, $F_{1}$ (spread the exams over the period of the exam) is formulated in Eq.(2):

$$
F_{1}=\frac{\sum_{i=1}^{n} \sum_{j=1}^{n} c_{i j} \cdot \text { proximity }\left(t_{i}, t_{j}\right)}{2 S}
$$

and 


$$
\operatorname{proximity}\left(t_{i}, t_{j}\right)=\left\{\begin{array}{cc}
\frac{32}{2\left|t_{i}-t_{j}\right|}, & \text { if } 1 \leq\left|t_{i}-t_{j}\right| \leq 5 \\
0, & \text { otherwise }
\end{array}\right.
$$

where $t_{i}$ and $t_{j}$ represent the timeslots allocated for exam $i$ and $j(i, j) \in\{1, \ldots, N\}$. Equation (2) represents the spreading cost for exam $i$, it can be calculated by multiplying the number of students in conflict with the proximity value. The proximity values used are 16, 8, 4, 2 and 1. For example, the value 16 represent the examinations schedule consecutive; value 8 represent the examinations schedule between a gap of timeslot, value 4 represent the examinations schedule between 2 gaps of timeslots, value 2 represent the examinations schedule between 3 gaps of timeslots and value 1 represent the examinations schedule between 4 gaps of timeslots. These proximity values were introduced by Carter, Laporte and, Lee (1996).

The second component of cost, distance cost, $F_{2}$ (distance between multiple rooms for a single exam) is formulated in Eq.(4):

$$
\mathrm{F}_{2}=\frac{\sum_{i=1}^{N} \sum_{r=1}^{R-1} \sum_{p=r+1}^{R} a_{r p} y_{i r} y_{i p}}{N}
$$

The third component of cost, splitting cost, F3 (splitting of rooms for a single exam) is formulated in Eq.(5):

$$
\mathrm{F}_{3}=\frac{\sum_{i=1}^{N} m_{i}-1}{N}
$$

where $m_{i}$ represents the number of the splitting for exam, $i$. It can be calculated by using the formulation shown in Eq.(6):

$$
m_{i}=\sum_{r=1}^{R} y_{i r} \forall i \in\{1, \ldots, N\}
$$

Equation (6) shows a cost of exam $i$ that is assigned to an exam that split into different rooms $\left(m_{i}>1\right)$. For example, the penalty value is 1 if a single exam is being split into two exam rooms and so on.

\section{RELATIONSHIP BETWEEN MODEL AND CONSTRAINTS IN UMP EXAMINATION TIMETABLING PROBLEM}

Equation (1) is subject to the following constraints:

a. No students are allowed to sit more than one examination simultaneously. The 
number of students that taking both exams $i$ and $j$ must be equal to zero, if the exam $i$ and $j$ are scheduled to timeslot $t$. Therefore, $c_{i j}=0$.

$$
\sum_{t=1}^{T} \sum_{i=1}^{N-1} \sum_{j=i+1}^{N} x_{i t} x_{j t} c_{i j}=0
$$

b. All the exams must be assigned only once in the timeslot, $T$.

$$
\sum_{t=1}^{T} x_{i t}=1 \text { for all } i \in\{1, \ldots, N\}
$$

where $N$ represents the total number of examination.

c. A single exam must be split into rooms in the same building.

$$
\sum_{r=1}^{R-1} \sum_{p=r+1}^{R} y_{i+} y_{i p} b_{r p}=\frac{m_{i}\left(m_{i}-1\right)}{2} \text { for all } i\{1, \ldots, N\}
$$

where

$$
b_{r p}=\left\{\begin{array}{c}
1, \text { if }\left(B_{r}=B_{p}\right) \\
0, \text { otherwise }
\end{array}\right.
$$

d. The number of exam rooms allocated to a specific timeslot must not exceed the number of available rooms in a specific timeslot, $R_{\mathrm{r}}$.

$$
\sum_{r=1}^{R} z_{r t} \leq R_{t} \text { for ald } t \in\{1, \ldots, T\}
$$

e. The number of students that allocated to a specific room must be less than the maximum room capacity.

$$
S_{i} \leq \sum_{r=1}^{R} y_{i r} f_{r} \quad \text { For add } i \in\{1, \ldots, N\}
$$

f. The exam needs to be scheduled to the appropriate campus. 


$$
\sum_{r=1}^{R} y_{i r} C_{r i}=0 \quad \text { For ald } i \in\{1, \ldots, N\}
$$

where

$$
C_{r i}=\left\{\begin{array}{c}
0, \text { if }\left(C_{r}=C_{i}\right) \\
1, \text { otherwise }
\end{array}\right.
$$

\section{EXPERIMENTAL SETUP}

In this section, we discuss our proposed model to evaluate the quality of examination timetable generated by UMP. The experiment dataset is taken from semester 1 , 2014/2015. The number of examinations, number of registered students, number of student enrolments, number of timeslots and number of exam rooms are collected. The total number of examination offered by UMP is 445 and the total number of students is 7833 with 31,185 student enrolments. The total available exam room for this dataset is 40 rooms and the capacity of each room is different. The number of examination days and timeslots are 15 and 30 respectively. There are two timeslots on each examination days and no exam will be assigned on Saturday and Sunday. Figure 1 shows the timeslot incides. In Figure 1, the timeslot 1 and 2 refer to day 1, timeslot 3 and 4 refer to day 2 and so on. The incides 11 to 14 and 25 to 28 are missing because those incides refer to weekend.

$$
\begin{aligned}
& (1,2,3,4,5,6,7,8,9,10,15 \\
& 16,17,18,19,20,21,22,23 \\
& 24,29,30,31,32,33,34,35 \\
& 36,37,38)
\end{aligned}
$$

Figure 1 Timeslot Incides

A study of UMP examination timetabling problem is carried out after collecting all the information. UMP currently situated in two campuses (Gambang and Pekan) which presents some additional hard and soft constraints. After investigating the hard and soft constraints, the mathematical model is developed in order to evaluate the quality of the examination timetable produced by UMP. The quality of the examination timetable is determined by calculating the total penalty cost which includes the spreading cost, distance cost and splitting cost. The spreading cost is calculated based on the gap of free timeslots between two examinations; the distance cost and splitting cost are calculated when more than one room assigned to an examination. Figure 2 shows the flow chart of the process. 


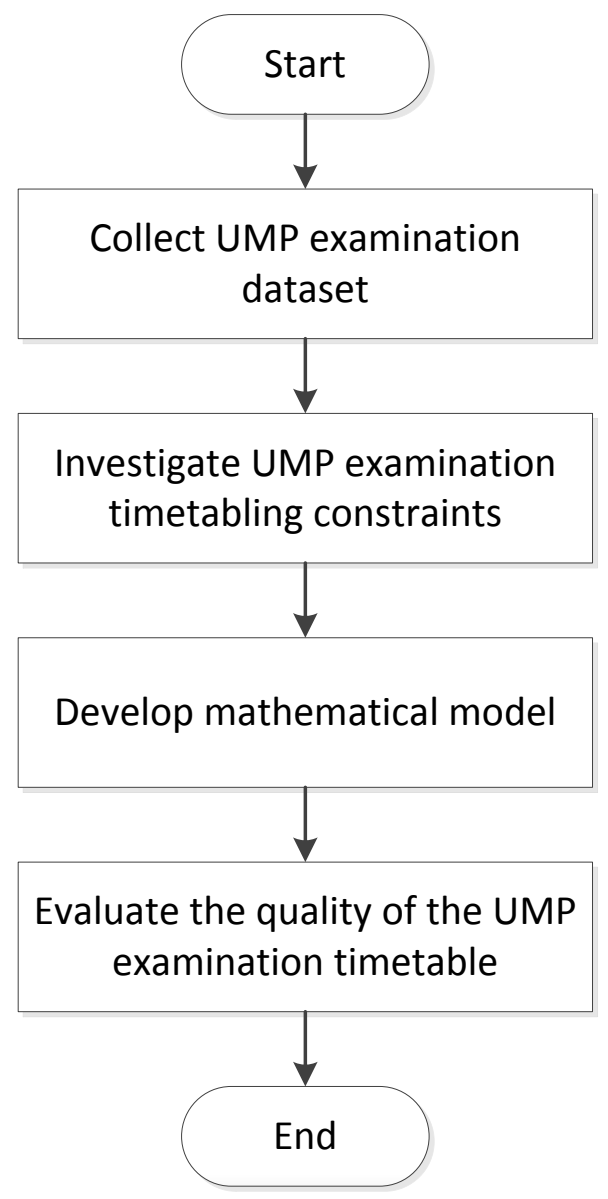

Figure 2 Flow Chart of the Process

\section{RESULTS AND DISCUSSION}

The discussion on the results of the UMP examination timetabling problem is presented in this section. Table 3 shows the result of the examination timetable generated by proprietary system.

Based on Table 3, it indicates that the examination timetable generated by UMP did not comply with some of the hard constraints. The examination timetable did not satisfy the constraints for no students are allowed to take two examinations simultaneously and a single exam must be split into rooms in the same building constraint. UMP had to quarantine two students because they were assigned to take two examinations simultaneously. Besides, 24 exams were assigned to the rooms in different buildings. 
Table 3 Result for UMP Examination Timetable generated

\begin{tabular}{|c|l|c|}
\hline \hline No & \multicolumn{1}{|c|}{ HARD ConstrainTs } & Result \\
\hline H1 & $\begin{array}{l}\text { No students are allowed to take two examinations } \\
\text { simultaneously. }\end{array}$ & Not comply \\
\hline H2 & $\begin{array}{l}\text { The number of students allocated to a specific exam room } \\
\text { must be less than the maximum capacity of room. }\end{array}$ & Comply \\
\hline H3 & Exam room can be shared with multiple exam papers. & Comply \\
\hline H4 & A single exam must be split into rooms in the same building. & Not comply \\
\hline H5 & The exam needs to be scheduled to the appropriate campus. & Comply \\
\hline \hline
\end{tabular}

The examination timetable quality is evaluated based on the three objectives. The penalty cost for the first objective is spreading cost, $F_{1}=11.30$; the second objective is distance cost, $F_{2}=529.44$ and the third objective is splitting cost, $F_{3}=0.62$. The total of the penalty cost is 541.36. The distance cost is high because some exams were assigned to the rooms that in different building and it causes the total penalty value become higher.

\section{CONCLUSION}

Examination timetabling is an important and challenging task faced by every academic institution (Laporte \& Desroches, 1984; Carter \& Laporte, 1996). Every academic institution has a different constraints and resources in producing the examination timetabling. Hence, the examination timetable should be generated independently to meet the individual requirements.

In this paper, a study of UMP examination timetabling problem and its additional constraints is presented. Besides, the quality of the UMP examination timetable produced is evaluated due to the three objectives and the penalty cost is calculated using the mathematical model. The penalty cost is high if the quality of the solution is bad. The examination timetable produced by the proprietary system shows a high penalty cost. This results that it is not a good quality examination timetable and it did not fulfill all the hard constraints.

\section{REFERENCES}

Abdullah, S. and Turabieh, H. (2012). On the use of multi-neighborhood structures within a Tabu-based memetic approach to university timetabling problems. Information Sciences 191(0), 146-168.

Abdullah, S., Turabieh, H., McCollum, B. and McMullan, P. (2010). A Tabu-Based Memetic Approach for Examination Timetabling Problems. Rough Set and Knowledge Technology 6401. Springer Berlin Heidelberg.

Abdullah S, (2006). Heuristic Approaches for University Timetabling Problems. Ph.D. Thesis, School of Computer Science and Information Technology, University of Nottingham, June 2006. 
Alzaqebah, M. and Abdullah, S. (2014). An adaptive artificial bee colony and lateacceptance hill-climbing algorithm for examination timetabling. Journal of Scheduling 17(3), 249-262.

Anwar, K., Khader, A. T., Al-Betar, M. A. and Awadallah, M. A. (2013). Harmony Search-based Hyper-heuristic for examination timetabling. 9th IEEE International Colloquium on Signal Processing and its Applications (CSPA), pp. 176-181.

Ayob, M., Ab Malik, A. M., Abdullah, S., Hamdan, A. R., Kendall, G. and Qu, R. (2007). Solving a practical examination timetabling problem: a case study. Computational Science and Its Applications-ICCSA 2007: Springer.

Ayob M, Abdullah S and Malik A M A, (2007). A Practical Examination Timetabling Problem at the Universiti Kebangsaan Malaysia, International Journal of Computer Science and Network Security, 7(9), pp 198-204.

Battistutta, M., Schaerf, A. and Urli, T. (2015). Feature-based tuning of single-stage simulated annealing for examination timetabling. Annals of Operations Research, $1-16$.

Burke, E. K. and Bykov, Y. (2012). The late acceptance hill-climbing heuristic (Technical report). University of Stirling, UK: CSM-192.

Burke, E. K., Newall, J. P. and Weare, R. F. (1996b). A memetic algorithm for university exam timetabling. Practice and Theory of Automated Timetabling: Springer.

Bykov, Y. and Petrovic, S. (2016). A Step Counting Hill Climbing Algorithm applied to University Examination Timetabling. Journal of Scheduling, 1-14.

Carter, M. W., Laporte, G. and Lee, S. Y. (1996). Examination timetabling: Algorithmic strategies and applications. Journal of the Operational Research Society 47(3), 373-383.

Carter, M. W. and Laporte, G. (1996). Recent developments in practical examination timetabling. Practice and Theory of Automated Timetabling 1153. Springer.

Gogos, C., Alefragis, P. and Housos, E. (2012). An improved multi-staged algorithmic process for the solution of the examination timetabling problem. Annals of Operations Research 194(1), 203-221.

Laporte $\mathrm{G}$ and Desroches S (1984). Examination timetabling by computer. Computers and Operations Research. 11, pages 351-360.

Kahar, M. N. M. and Kendall, G. (2010). The examination timetabling problem at Universiti Malaysia Pahang: Comparison of a constructive heuristic with an existing software solution. European Journal of Operational Research 207(2), 557-565.

Kendall, G. and Hussin, N. M. (2005a). An investigation of a tabu-search-based hyperheuristic for examination timetabling. Multidisciplinary Scheduling: Theory and Applications: Springer.

Kendall, G. and Hussin, N. M. (2005b). A tabu search hyper-heuristic approach to the examination timetabling problem at the MARA university of technology. Practice and Theory of Automated Timetabling V: Springer.

McCollum B, McMullan P, Burke E K, Parkes A J and Qu R, (2008). The second international timetabling competition: Examination timetabling track. Technical 
Report QUB/IEEE/Tech/ITC2007/Exam/v1.0/1. Queen"s Belfast University, N. Ireland.

Merlot, L. T., Boland, N., Hughes, B. D. and Stuckey, P. J. (2003). A hybrid algorithm for the examination timetabling problem. Practice and theory of automated timetabling IV: Springer.

Pillay, N. and Banzhaf, W. (2009). A study of heuristic combinations for hyperheuristic systems for the uncapacitated examination timetabling problem. European Journal of Operational Research 197(2), 482-491.

Sabar, N. R., Ayob, M., Kendall, G. and Qu, R. (2012a). A honey-bee mating optimization algorithm for educational timetabling problems. European Journal of Operational Research 216(3), 533-543.

Turabieh, H. and Abdullah, S. (2011b). An integrated hybrid approach to the examination timetabling problem. Omega-International Journal of Management Science 39(6), 598-607. 